\title{
MEDICINE
}

\section{PREDISPOSING FACTORS AND TREATMENT OF OSTEOARTHRITIS AFTER SURGERIES PERFORMED FOR TIBIAL FRACTURES}

\author{
PhD, Associate Professor Dudko O. G., ${ }^{1,2}$ \\ PhD, Associate Professor Glubochenko O. V., ${ }^{1}$ \\ Orthopaedic surgeon Pickula $\boldsymbol{V} . V_{.,}{ }^{2}$ \\ PhD, Assistant Professor Marchuk O. F., ${ }^{1}$ \\ PhD, D.Tech.Sci, Professor Shayko-Shaykovskiy O. G. ${ }^{3}$ \\ Ukraine, Chernivtsi City, \\ ${ }^{1}$ HSEEU "Bukovynian State Medical University" \\ ${ }^{2}$ Chernivtsi Emergency City Hospital \\ ${ }^{3}$ Yuriy Fedkovych Chernivtsi National University, General Physics Department
}

DOI: https://doi.org/10.31435/rsglobal_ws/30122019/6825

\begin{abstract}
ARTICLE INFO
Received: 14 October 2019

Accepted: 19 December 2019

Published: 30 December 2019

\section{KEYWORDS}

tibial fractures,

osteoarthritis,

surgical treatment,

outcomes.

ABSTRACT

Tibial fractures are very common injuries that require surgical management. For many cases, when the fracture involves the joint further complications occur, such as joint stiffness, osteoarthritis, aseptic necrosis of articular surfaces, ankylosis, infection complications, etc. To prevent joint stiffness open reduction and internal fracture fixation is used. That allows better positioning of fracture fragments forming joint surface and improve outcome. The article analyses results of surgical treatment of intraarticular fractures as well as biomechanical factors that are affecting the joint within the healing process and in later outcome period. Various treatment procedures are suggested to prevent development of osteoarthritis or to decrease its severity. The following options are used on all stages of treatment starting since the moment of injury, primary surgical procedures, rehabilitation period, and further non-surgical treatment in the internal medicine department. Important roles are assigned for use of chondroprotective drugs, intraarticular injections of Hyaluronic acid, physiotherapy and physical activity.
\end{abstract}

Citation: Dudko O. G., Glubochenko O. V., Pickula V. V., Marchuk O. F., Shayko-Shaykovskiy O. G. (2019) Predisposing Factors and Treatment of Osteoarthritis after Surgeries Performed for Tibial Fractures. World Science. 12(52), Vol.1. doi: 10.31435/rsglobal_ws/30122019/6825

Copyright: (C) 2019 Dudko O. G., Glubochenko O. V., Pickula V. V., Marchuk O. F., ShaykoShaykovskiy O. G. This is an open-access article distributed under the terms of the Creative Commons Attribution License (CC BY). The use, distribution or reproduction in other forums is permitted, provided the original author(s) or licensor are credited and that the original publication in this journal is cited, in accordance with accepted academic practice. No use, distribution or reproduction is permitted which does not comply with these terms.

Actuality. The annual grow of injuries of locomotor system and bone fractures in World Health requires well-trained specialists and new treatment modalities to solve the problem. This tendency was found in USA for 1990 - 2010 years period, and is very similar in other countries [1]. Among all fractures tibial fractures are very disabling and occur in $12,1 \%$ of cases. The most common reasons are: vehicle accidents, sports injuries, that happens in 19-22 patients per 10000 population in Europe and North America. In many cases these fractures require surgical management. For fractures involving the joint surface further complications occur, such as joint stiffness, osteoarthritis, aseptic necrosis of articular surfaces, ankylosis, infection complications, etc [2, 3, 4]. The factors that affect treatment results may be patient related, injury related and doctor related, so the last one we can 
improve by implementation of modern and advanced education on all steps of doctors training student, resident, young doctor [5]. To prevent joint stiffness open reduction and internal fracture fixation is used. That allows better positioning fracture fragments forming joint surface and improve outcome. Osteoarthritis is one of the most unwanted outcomes. One of the main goals of treatment is to prevent its development and progression to the advanced stage. In many cases advanced osteoarthritis should be treated with total knee arthroplasty or total ankle arthroplasty later on, with significant expenses $[6,7,8]$. As surgical management of these injuries remains controversial - some authors advocates external fixators application, others - primary joints arthroplasties, but for majority of them internal fracture fixation is the main choice $[9,10,11,12]$.

The aim of research was to analyses treatment results of patients with tibial intraarticular and periarticular fractures after surgical treatment.

Materials and methods. The study was performed in Traumatology and Orthopaedics clinical department of Bukovinian State Medical University based in Chernivtsi Emergency City Hospital and Propedeutics of Internal Medicine department of Bukovinian State Medical University since 01.01.2018 till 30.11.2019. Clinical cases when intraarticular and periarticular fractures of proximal and distal ends of tibia were treated with internal fracture fixation with plates and screws. The followup was performed within the period from three months to 26 months with average of 12.5 months. The following methods of examination were used - clinical, radiographic, CT and MRI tomography.

Results and discussion. Surgical treatment of intraarticular tibial fractures was performed in 186 patients with certain fractures and 106 patients of them (57\%) were available for follow-up. AO principles of fracture management were used according to the fracture pattern that was previously analysed [13]. Those were 55 cases of proximal tibia fractures, and 51 case of distal tibia fractures (including malleolus). Fractures were divided in tree groups - fractures surrounding joint but not involving its articular surface, fractures partially involving articular surface of knee or ankle joint, and fractures completely involving articular surface. All fractures that underwent surgical treatment were displaced fractures where the level of displacement was greater then $2 \mathrm{~mm}$ and those that required open reduction. Standard surgical approaches were used [14, 15, 16, 17]. Previous attempts of close reduction failed or were not performed, as it was considered not possible basing on our clinical experience to reduce these fractures in a close way. Average period of surgery was from 7 to 12 days after admitting to the hospital, as early surgical procedures is not recommended by many authors [18, $19,20,21]$. Within this period skeletal extension was used to immobilize distal tibial fractures that was applied at the calcanial bone. In some cases external fixators were used as first step. For proximal tibial fractures skeletal extension was used only for cases with severe displacement. For fractures with some impaction of tibial condyles brace was used instead. Non-surgical treatment included diuretics (furosemid $20 \mathrm{mg}$ twice per day), L-lysin-escenate $10 \mathrm{ml}$ intravenously daily. Surgeries were performed on the day when swelling was decreased.

Patients that were included in the study were cases when locking heard screws and plates were used for fracture fixation. No other external support - brace or plaster bandage were used. Early movements were allowed for all patient just after sutures were removed. The follow-up X-rays were performed in 1, 2, 3, 6 and 12 mount period to check the process of fracture healing and the state of joint surface. There were 12 patients with osteoarthritis revealed in the follow-up, 4 cases for the ankle joint, and 8 for the knee joint. Those patients were complaining on pain and restriction of movement in joint in different periods after surgical treatment. As it was previously described by Rashid et al [22] there are some cases of proximal tibial fractures that were present already before the fracture, and were revealed on preoperative and after operative X-rays. In these cases degenerative changes are usually progressing after fracture despite correct surgical treatment and after surgical care. There were 5 cases in our study with osteoarthritis of knee (4 cases) and ankle (1 case) joint that were developed in more progressive stage after surgical treatment. The patients with osteoarthritis were treated later-on in either Traumatology or in the Internal Medicine departments with administration of nonsteroid antiinflamentory drugs, local physiotherapy, massages, non- or partially weight-bearing exercises, chondroprotective drugs containing glucoseaminoglycans and hondroitinsulfate twice dally for 1 month and once per day for the next tree months. 7 patients were additionally treated with intraarticulary injections of chondroprotective drugs hyaluronic acid 1,8\%-2,0 ml were injected 5 times with the interval of one week. In all cases we observe clinical improvement, but for the cases when intraarticular injections were performed the pain relieve started earlier and was more prolonged. Though results of intraarticulary injections of hyaluronic acid in 
some studies are controversial, our clinical experience show improvement after these procedures [23]. As an example we can present a clinical case of patient K, 41 y.o. that was admitted in 3 month after surgery. Open reduction internal fixation of comminuted fracture of distal metaepiphyses of tibia and fibular bones with plates and screws was performed. X-rays shows signs of fractures healing and moderate osteoarthritis of left ankle joint (Fig. 1). It was developed despite of the nice reduction due to the high energy mechanism of injury. Clinically the patient was complaining on painful movement in left ankle joint, though he was applying partial weight bearing for it. There was local swilling and some joint stiffness in the joint. After treatment course patient got significant pain relive and was discharged for ambulatory treatment.

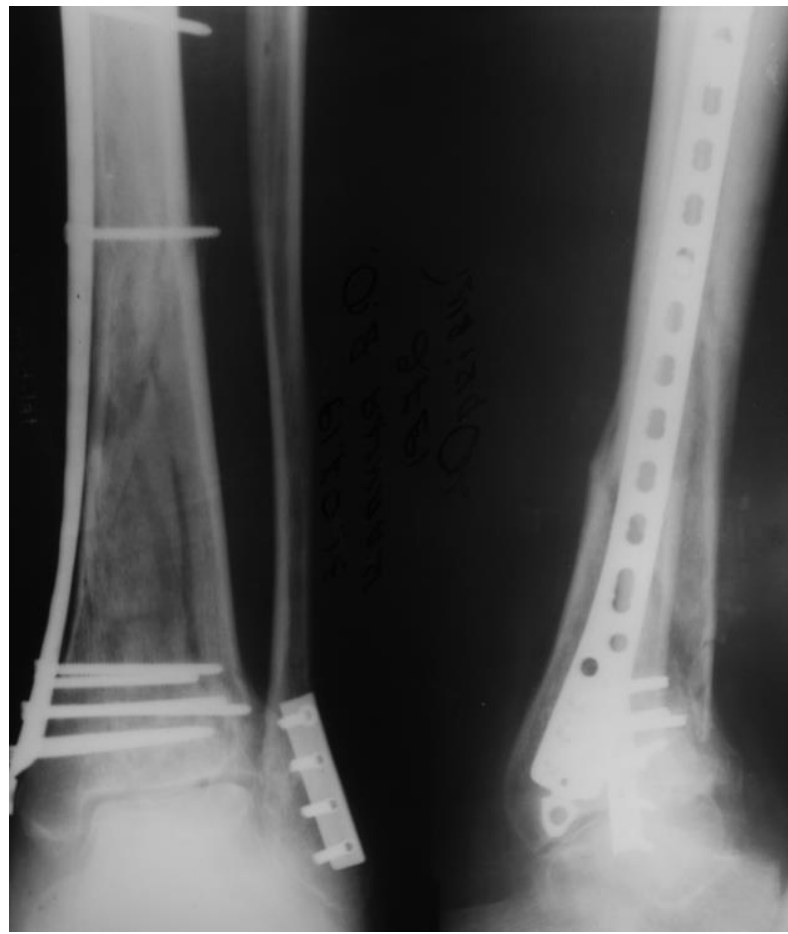

Fig.1. Patient K, 42 y.o., 3 month after surgery - open reduction and internal fracture fixation of comminuted fracture of distal metaepiphysis of tibia and fibular with plates and screws

As there were 12 patients with OA it was up to $11,7 \%$ of those patients that were followed-up. Compared with reported by Harris et al $39 \%$ of such complications that were significantly less [24]. But taking into account that almost one third of his cases were open fractures with much higher potential for development of osteoarthritis. His study presented 11 cases of osteoarthritis in open fracture group. Those were treated with ring external fixator with no early movement in ankle joint. And even some other close fractures presented in the study were fixed with external fixator with no early movement in the joint, that we consider as predisposing factor for development of osteoarthritis. In our study vice a verse all fractures were close and early movements were applied, that in our opinion improved local blood supply, muscles activity and was considered, as positive factor for prevention of osteoarthritis [25, 26, 27]. Another positive factor was early removal of metal fixation devices. In our patients average removal rate for distal tibial fractures was $28,6 \%$, and for proximal tibial fractures it was $35,6 \%$. Those surgeries were performed in the first 1-2 years and that slower down the development of osteoarthritis. Though despite severity of these injuries proper management can led to good and satisfactory results for these fractures [28].

Conclusions. Results of treatment depend from many factors, such as quality of surgical reduction of bone fragments, stability of fixation, active movements and late weight bearing. Important role the treatment in rehabilitation period plays such factors, as warming procedures, chondroprotective drug administration, intraarticular injection of hyaluronic acid, stretching physical exercises. These methods allow to decrees amount of cases with severe osteoarthritis, as well as slow down the process for other cases with intraarticular fractures that underwent open reduction and internal fracture fixation. 


\section{REFERENCES}

1. Murray Christopher JL. (2013). The State of US Health, 1990-2010. Burden of diseases, injuries, and risk factors. JAMA, $310(6), 591-608$.

2. Aurich, M., Koenig, V., \& Hofmann, G. (2018). Comminuted intraarticular fractures of the tibial plateau lead to posttraumatic osteoarthritis of the knee: Current treatment review. Asian Journal of Surgery, 41(2), 99-105.

3. Biz, C., Maso, G., Gambato, M., Belluzzi, E., Pozzuoli, A., Favero, M., et al. (2019). Challenging surgical treatment of displaced articular tibial plateau fractures: do early knee radiographic features have a predictive value of the mid-term clinical functional outcomes? Orthopaedic Surgery, Nov, 1-12.

4. Bourne, R. B., Rorabeck, C. H., \& Macnab, J. (1983). Intra-articular fractures of the distal tibia - the pilon fracture. Journal of Trauma-Injury Infection and Critical Care, 23(7), 591-596.

5. Dudko O.G. (2018). Managing "Traumatology and orthopedics" educational course for foreign students in Bukovynian State Medical University. Medical Education, 1, 125-28.

6. Bennett A, Ramaskandhan J, Siddique M. Total Ankle Replacement for Osteoarthritis Following Pilon Fracture of the Tibia. Foot \& Ankle International. 2018;39(9):1008-18.

7. Soundarrajan D, Rajkumar N, Dhanasekararaja P, Rajasekaran S. Proximal tibia stress fracture with osteoarthritis of knee - Radiological and functional analysis of one stage TKA with long stem. Sicot-J. 2018;4.

8. Bennett, A., Ramaskandhan, J., \& Siddique, M. (2018). Total Ankle Replacement for Osteoarthritis Following Pilon Fracture of the Tibia. Foot \& Ankle International, 39(9), 1008-1018.

9. Bohm, E. R., Tufescu, T. V., \& Marsh, J. P. (2012). The operative management of osteoporotic fractures of the knee TO FIX OR REPLACE? Journal of Bone and Joint Surgery-British Volume, 94B(9), 1160-1169.

10. Hill, C. E. (2016). Does external fixation result in superior ankle function than open reduction internal fixation in the management of adult distal tibial plafond fractures? Foot and Ankle Surgery, 22(3), 146-151.

11. Pape, D., Hoffmann, A., Gerich, T., Van der Kerkhofe, M., Weber, M., \& Pape, H. C. (2014). Fractures of the knee joint in the elderly. Osteosynthesis versus joint replacement. Orthopade, 43(4), 365-373.

12. Ruedi, T. P., \& Allgower, M. (1979). Operative treatment of intra-articular fractures of the lower end of the tibia. Clinical Orthopaedics and Related Research(138), 105-110.

13. Mukhopadhaya J, Jain AK. (2019). AO Principles of Fracture Management. Indian J Orthop., 53(1), $217-218$.

14. Grose, A., Gardner, M. J., Hettrich, C., Fishman, F., Lorich, D. G., Asprinio, D. E., et al. (2007). Open reduction and internal fixation of tibial pilon fractures using a lateral approach. Journal of Orthopaedic Trauma, 21(8), 530-537.

15. Grose, A., Gardner, M. J., Hettrich, C., Fishman, F., Lorich, D. G., Asprinio, D. E., et al. (2007). Open reduction and internal fixation of tibial pilon fractures using a lateral approach. Journal of Orthopaedic Trauma, 21(8), 530-537.

16. Karas, E. H., Weiner, L. S., \& Yang, E. C. (1996). The use of an anterior incision of the meniscus for exposure of tibial plateau fractures requiring open reduction and internal fixation. Journal of Orthopaedic Trauma, 10(4), 243-247.

17. Pawar, K. A., Panjwani, T. R., Panase, J. B., \& Sancheti, P. K. (2015). Management of comminuted fractures of lower extremity with minimally invasive plate osteosynthesis. Journal of Evolution of Medical and Dental Sciences-Jemds, 4(61), 10687-10696.

18. Conroy, J., Agarwal, M., Giannoudis, P. V., \& Matthews, S. J. E. (2003). Early internal fixation and soft tissue cover of severe open tibial pilon fractures. International Orthopaedics, 27(6), 343-347.

19. Lobenhoffer, P., Gerich, T., Bertram, T., Lattermann, C., Pohlemann, T., \& Tscherne, H. (1997). Treatment of posterior tibial plateau fractures via posteromedial and posterolateral exposures. Unfallchirurg, 100(12), 957-967.

20. Olivera, R., Machain, S., \& Filomeno, P. (2016). Surgical management strategies in high energy plafond tibial fractures. Sistematic review. Anales De La Facultad De Medicina-Universidad De La Republica Uruguay, 3(1), 25-36.

21. Prat-Fabregat, S., \& Camacho-Carrasco, P. (2016). Treatment strategy for tibial plateau fractures: an update. Efort Open Reviews, 1(5), 225-232.

22. Rashid RH, Zubairi AJ, Umer M, Hashmi PM, Lakdawala RH. Management of stress fractures of the proximal tibia in patients with advance knee osteoarthritis. A case series. Acta Orthopaedica Belgica. 2018;84(4):436-42.

23. Barakat, A. S., Ibrahim, N. M., Elghobashy, O., Sultan, A. M., \& Abdel-Kader, K. F. M. (2019). Prevention of post-traumatic osteoarthritis after intra-articular knee fractures using hyaluronic acid: a randomized prospective pilot study. International Orthopaedics, 43(11), 2437-2445.

24. Harris, A. M., Patterson, B. M., Sontich, J. K., \& Vallier, H. A. (2006). Results and outcomes after operative treatment of high-energy tibial plafond fractures. Foot \& Ankle International, 27(4), 256-265.

25. Domsic, R. T., \& Saltzman, C. L. (1998). Ankle osteoarthritis scale. Foot \& Ankle International, 19(7), $466-471$.

26. Rashid, R. H., Zubairi, A. J., Umer, M., Hashmi, P. M., \& Lakdawala, R. H. (2018). Management of stress fractures of the proximal tibia in patients with advance knee osteoarthritis. A case series. Acta Orthopaedica Belgica, 84(4), 436-442.

27. Soundarrajan, D., Rajkumar, N., Dhanasekararaja, P., \& Rajasekaran, S. (2018). Proximal tibia stress fracture with osteoarthritis of knee - Radiological and functional analysis of one stage TKA with long stem. Sicot-J, 4.

28. Van Dreumel, R. L. M., van Wunnik, B. P. W., Janssen, L., Simons, P. C. G., \& Janzing, H. M. J. (2015). Mid- to long-term functional outcome after open reduction and internal fixation of tibial plateau fractures. Injury-International Journal of the Care of the Injured, 46(8), 1608-1612. 